\title{
Non-Mulberry and Mulberry Silk Protein Sericins as Potential Media Supplement for Animal Cell Culture
}

\author{
Neety Sahu, ${ }^{1}$ Shilpa Pal, ${ }^{1}$ Sunaina Sapru, ${ }^{1}$ Joydip Kundu, ${ }^{1}$ Sarmistha Talukdar, \\ N. Ibotambi Singh, ${ }^{2}$ Juming Yao, ${ }^{3}$ and Subhas C. Kundu ${ }^{1}$ \\ ${ }^{1}$ Department of Biotechnology, Indian Institute of Technology Kharagpur, West Bengal 721302, India \\ ${ }^{2}$ Central Muga Eri Research and Training Institute, Lahdoigarh, Jorhat, Assam 785700, India \\ ${ }^{3}$ The Key Laboratory of Advanced Textile Materials and Manufacturing Technology of Ministry of Education, \\ College of Materials and Textiles, Zhejiang Sci-Tech University, Hangzhou 310018, China
}

Correspondence should be addressed to Subhas C. Kundu; kundu@hijli.iitkgp.ernet.in

Received 24 February 2016; Revised 25 May 2016; Accepted 6 June 2016

Academic Editor: Max Costa

Copyright (C) 2016 Neety Sahu et al. This is an open access article distributed under the Creative Commons Attribution License, which permits unrestricted use, distribution, and reproduction in any medium, provided the original work is properly cited.

\begin{abstract}
Silk protein sericins, in the recent years, find application in cosmetics and pharmaceuticals and as biomaterials. We investigate the potential of sericin, extracted from both mulberry Bombyx mori and different non-mulberry sources, namely, tropical tasar, Antheraea mylitta; muga, Antheraea assama; and eri, Samia ricini, as growth supplement in serum-free culture medium. Sericin supplemented media containing different concentrations of sericins from the different species are examined for attachment, growth, proliferation, and morphology of fibrosarcoma cells. The optimum sericin supplementation seems to vary with the source of sericins. The results indicate that all the sericins promote the growth of L929 cells in serum-free culture media; however, S. ricini sericin seems to promote better growth of cells amongst other non-mulberry sericins.
\end{abstract}

\section{Introduction}

Silk protein sericin (glue protein) is a water soluble glycoprotein that shields the fibroin fibres present in the cocoon. This cocoon structure protects the pupae from the different environmental conditions, natural calamities, and predators (particularly for non-mulberry silkworms) stress. The gluelike strong adhesive nature of this protein is attributed to the hydrogen bonding capability of the enormous number of hydroxyl amino acids present in it. The removal of sericin from the silk fibres is carried out by the different processes called degumming. The sericins are mostly discarded as waste products during silk fibre processing in the textile industries, which now find place in economics. If the sericins are recovered and recycled properly, then this may play significant role in social benefits. Sericin recently finds widespread applications in cosmetic industry, as antioxidant and antiapoptotic compound, as support for enzyme immobilization, as supplement in animal cell culture media, as dietary supplement, and also as biomaterial for cell culture, drug, and gene delivery [1-8]. Addition of $0.5 \%$ sericin to cell culture medium improved the resistance to oxidative stress and quality of bovine embryos in vitro [9].

Sericin is isolated from the silk cocoons by the degumming process, which takes the advantage of the solubility of sericin in boiling aqueous solutions containing reagents like soap, alkali, synthetic detergents, urea, organic acids, and proteolytic enzymes. The most common methods used for the removal of sericin from cocoons are either by heating or by alkali treatment [10]. Mosher and Rayon in 1934 isolated sericin by boiling cocoons in hot water and separated them as water soluble and water insoluble fractions [11]. Usually in the silk industry, degumming of cocoons is carried out by alkaline condition utilizing either $\mathrm{Na}_{2} \mathrm{CO}_{3}$ or $\mathrm{NaOH}$ followed by boiling for 30 mins. Three types of polypeptides of mulberry silk sericin are obtained using isolation buffer, which contains $8 \mathrm{M}$ urea, $1 \%$ SDS, and $2 \% \beta$-mercaptoethanol for 30 mins at room temperature, followed by heating at $80^{\circ} \mathrm{C}$ [12]. For isolating sericin in the native condition, the cut cocoons and peduncle pieces are soaked in $1 \% \mathrm{NaCl}$ solution at room 
temperature overnight with shaking at $100 \mathrm{rpm}$ followed by precipitation and resolubilization [13-15]. Sericin displays the ability to self-assemble via multiple aggregation mechanisms [16].

Sericin obtained from mulberry Bombyx mori contains a group of proteins ranging from 20 to $400 \mathrm{kDa}$ and has an unusually high serine content (40\%) along with significant glycine content (16\%) [6]. Secondary structure of sericin from the cocoons of $B$. mori reveals the presence of $\beta$-sheet structure along with random coils [17]. The sericin of Indian non-mulberry tropical silkworm Antheraea mylitta has three prominent polypeptides of $70 \mathrm{kDa}, 200 \mathrm{kDa}$, and a higher fraction of more than $200 \mathrm{kDa}$ [14].

Low molecular weight sericin is reported to have myriad applications in biomedical, cosmetic, and pharmaceutical industries, as bioconjugates in drug delivery and graft copolymers. Sericin from $B$. mori mutant silkworm, sericin hope, a mutant of Bombyx mori and deficient of fibroin, is shown to be a new natural silk biomaterial for dermal equivalent for grafting. The fibroblast-keratinocyte coculture on 3D sericin hope matrix model is reported to be an alternative to in vitro skin replacement grafts [7]. A. mylitta sericin coated titanium surfaces are also reported to have potential application in titanium based medical implants [18]. Mulberry sericin is used as blended biomaterial scaffolds to promote healing in injured tissues $[19,20]$. Non-mulberry sericin is also used to promote dermal reconstruction [21]. Therefore, the idea that the sericin may have a role in promoting growth and proliferation of cells apart from its uses as a biomaterial holds promise. Sericin from mulberry B. mori is shown to accelerate cell proliferation in serum-free mammalian cell culture [22]. Apart from its applications in tissue engineering and healthcare industries, sericin is also reported to act as an alternative to serum in the culture of islet cells [23, 24]. Sericin is shown to prevent cell death and promote cellular growth in Sf9 insect cells after acute serum deprivation [25]. A novel serum-free freezing medium consisting of PBS, $1 \%(\mathrm{v} / \mathrm{w})$ sericin, $0.5 \%(\mathrm{v} / \mathrm{w})$ maltose, $0.3 \%(\mathrm{v} / \mathrm{w})$ proline, $0.3 \%(\mathrm{v} / \mathrm{w})$ glutamine, and $10 \%$ DMSO is developed and is found to be better than the conventional serum containing freezing media for the cryopreservation of P3U1 myeloma cell line, Chinese-hamster ovary cells, human dermal fibroblasts, human epidermal keratinocytes, the rat pheochromocytoma cell line PC12, and insect cell line Sf9 [26]. Bovine embryos are preserved well in sericin supplemented serum-free freezing media [27]. Serum-free medium containing sericin is shown to be suitable not only for cell culture but also for cryopreservation rat islets [28]. It has been shown that sericin may substitute for FBS in the freezing medium for primary hMSCs but cannot substitute for DMSO [29]. Though serum is widely used as a growth supplement in cell culture media, some potential disadvantages of serum limit its use in pharmaceuticals industries. These are (1) higher level of contaminants, the protein concentration in $10 \%$ serum being 6,200-10,1000 mg/L; (2) presence of various other components besides growth factors; (3) potential source of infectious agents, viral, bacterial, and fungal contamination of serum; and (4) high cost and availability [30]. The role of sericin in the growth of animal cells holds an advantage over serum. This holds true in cases where high level of purity of recovered cellular products is desired [22]. Moreover, silk sericin is an inexpensive alternative to serum in this regard. The sericins are low-cost abundant waste/by-product of silk textile industries and until now are underutilised. The application of sericin protein as biomaterial is documented in the literature $[1,6]$. The useful properties of sericin like being antioxidant and antiapoptotic, hydrophilicity, and potential to promote cell attachment and growth provide the added characteristics for the use of sericin in the fabrication of various matrices (films, mats, 3D scaffolds, hydrogels, and nanoparticles) in diversified fields of tissue engineering and regenerative medicine (6). High solubility and weak structural composition make silk sericin very fragile and unsuitable for fabricating biomedical materials [31]. However, silk sericins are used to fabricate tenable materials for use in tissue engineering by some biochemical modifications $[4,31]$. Our and other similar investigations $[23,24]$ indicate the ability of silk sericin to promote cell proliferation in serum-free culture media. This makes sericin an attractive component in the fabrication of biodegradable materials like hydrogels, films, and scaffolds, especially for the culture of cells that are susceptible to serum.

In this study, we investigate the biochemical, biophysical characteristics and the potential of the silk protein sericins as supplement to animal cell culture medium. The sericins are isolated from mulberry (Bombyx mori) and also different non-mulberry species (tropical tasar, Antheraea mylitta; muga, Antheraea assama; and eri, Samia ricini). The results indicate that the sericins may be used as potential supplements in place of serum for animal cell culture. This replacement with sericin may help future cell based tissue engineering and regenerative medicine practices.

\section{Experimental}

2.1. Materials. Live silk cocoons of mulberry silkworm, Bombyx mori (local farm), and non-mulberry Indian tropical tasar, Antheraea mylitta (our IIT farm), obtained from West Midnapore District, West Bengal State; non-mulberry muga silkworm Antheraea assama/Antheraea assamensis obtained from Cooch Behar District, West Bengal State; eri Samia ricini/Philosamia ricini silk cocoons obtained from Jalpaiguri Silk Farm, West Bengal State, India; and sericin hope (mutant of $B$. mori) obtained from China were collected for this study. The fine chemicals (St. Luisa, Sigma, USA, and Merck, India); protein molecular weight marker (Amersham, UK, Fermentas); Alamar Blue (Invitrogen, USA); cell culture grade chemicals, namely, Dulbecco's modified eagle medium (DMEM), fetal calf serum, trypsin-EDTA, and penicillin-streptomycin antibiotics (Gibco BRL, USA); and rhodamine-phalloidin and Hoechst, 33342 (Molecular Probes, USA), were purchased for this experimentation. Murine fibrosarcoma cell line, L929 (National Centre for Cell Science (NCCS), Pune, India), was maintained in DMEM supplemented with 10\% fetal bovine serum (FBS) and $50 \mu \mathrm{g} / \mathrm{mL}$ penicillin-streptomycin in $5 \% \mathrm{CO}_{2}$ incubator till they attained confluency. 
2.2. Isolation of Silk Sericins from the Silk Cocoons. The sericins were isolated individually from mulberry (B. mori) and non-mulberry (A. mylitta, S. ricini, A. assama, and sericin hope (containing about $98 \%$ sericin)) silk cocoons following the protocols modified from Zhang et al. [32] and Dash et al. [13]. In brief, the cocoons were cut into small pieces, degummed by boiling the cocoons in deionised water with a mass to liquid ratio (MLR) (w/v) of 1:20 under pressure using an autoclave at $110-120^{\circ} \mathrm{C}$ for 60 mins in cases of nonmulberry species (A. mylitta, S. ricini, and A. assama) and 30 mins for mulberry species (B. mori and sericin hope). Another extraction method as described by Takasu et al. [12] was followed for analysing the different polypeptide fractions of sericins present in the different species. The cocoon pieces were weighed and soaked in $8 \mathrm{M}$ urea containing $2 \% \beta$ mercaptoethanol and $1 \%$ SDS, followed by incubation at $80^{\circ} \mathrm{C}$ for 5 minutes. The sericin solutions were centrifuged at $800 \mathrm{rpm}$ for 10 minutes and supernatant so obtained was dialyzed using cellulose tubes $(3.5 \mathrm{kDa})$ against deionised water for $8-12 \mathrm{hrs}$ with regular change of water intermittently. They were filtered using $0.45 \mu \mathrm{m}$ pore size filters. The sericin powders were obtained individually by lyophilizing the sericin solutions and stored at $4^{\circ} \mathrm{C}$ until use.

2.3. Scanning Electron Microscopy (SEM). SEM images of the degummed cocoons were obtained after gold sputtering using a JEOL JSM-5800 scanning electron microscope with incident electron beam energy of $1 \mathrm{keV}$ and a working distance of $6 \mathrm{~mm}$.

\subsection{Characterization of Sericins}

2.4.1. Estimation of Molecular Weight through SDS-PAGE. The molecular weight distribution of the sericin obtained using urea method [12] and the autoclave method was verified by SDS-PAGE. About $0.1-0.2 \mathrm{mg}$ of the sericin samples that were isolated from the cocoons of B. mori, A. mylitta, S. ricini, and $A$. assama using hot boil degumming were incubated with Laemmli sample loading buffer. The proteins were loaded onto a $5 \%$ stacking gel cast on the top of an $8 \%$ SDS polyacrylamide gel (Merck) and electrophoresed. The gel was run at a constant voltage of $80 \mathrm{~V}$ for approximately $3 \mathrm{hrs}$ so that the protein is resolved efficiently. After electrophoresis, the gel was stained with Coomassie Brilliant Blue R-250 (Sigma, USA) and destained in a methanol/water $1: 1$ solution that contained $20 \%$ acetic acid. To visualize the bands not observed by Coomassie stain, silver staining [33] was performed. Briefly, the gels were immersed in a fixative solution (40\% methanol, 10\% acetic acid, and 50\% deionised water) for $1 \mathrm{hr}$. They were then washed with $30 \%$ ethanol thrice for 20 minutes each after which the gels were sensitized in the reductant $(0.02 \%$ sodium thiosulphate) for 2 mins and washed thoroughly with deionised water. The gels were then stained with $0.1 \%$ silver nitrate (Merck) solution and $0.02 \%$ formaldehyde (Merck) for an hour, washed, and developed using 3\% sodium carbonate (Sigma), 0.05\% formaldehyde (Sigma, USA), and $0.5 \%$ sodium thiosulphate (Sigma, USA) until the bands appeared. When the desired intensity was achieved, the reaction was terminated using 5\% acetic acid (Merck) solution.

2.4.2. Circular Dichroism (CD) Spectroscopy. The circular dichroism (CD) studies of cocoon sericins from different species were performed on a JASCO J-810 spectropolarimeter using a $0.1 \mathrm{~cm}$ path length quartz cell at $20^{\circ} \mathrm{C}$. The spectra were corrected for the baseline. The UV spectrum of the individual sericins was collected at a protein concentration of $0.1 \%(\mathrm{w} / \mathrm{v})$ in water. The data points were recorded with a step resolution of $0.5 \mathrm{~nm}$, time constant of $1 \mathrm{~s}$, sensitivity of $10 \mathrm{~m} \mathrm{deg}$, scan speed of $50 \mathrm{~nm} / \mathrm{min}$, and spectral bandwidth of $2 \mathrm{~nm}$. In order to reduce error and noise, each spectrum was an average of three scans over 400-190 nm. The background spectra were acquired from the same solvent. The spectra were corrected for the baseline and normalized to protein concentration in order to obtain the mean residue molar $\left(\mathrm{deg} \mathrm{cm}^{2} / \mathrm{d} \mathrm{mol}\right)$. The percentages of $\alpha$-helix, $\beta$-sheet, turns, and random coil were determined using the standard protein secondary structure estimation program provided inbuilt with JASCO J-810 spectropolarimeter [34].

2.4.3. Fourier Transform Infrared (FTIR) Spectroscopy. FTIR analysis of the sericin protein (powders) was carried out using an FTIR spectrometer (Thermo Nicolet Corporation NEXUS-870) with a resolution of $2 \mathrm{~cm}^{-1}$ with a scan range of $500 \mathrm{~cm}^{-1}$ to $2000 \mathrm{~cm}^{-1}$.

2.4.4. Thermogravimetric Analysis. Thermogravimetric analysis (TGA) was run under the flow of nitrogen gas from 30 to $650^{\circ} \mathrm{C}$ at a scanning speed of $20^{\circ} \mathrm{C} / \mathrm{min}$ using Pyris Diamond.

2.5. Cell Culture. Approximately $10^{3}$ mouse fibrosarcoma cells (L929) per well were seeded in 24-well tissue culture plates with DMEM (Dulbecco's Modified Eagle's Medium), supplemented with $10 \%$ fetal bovine serum, and allowed to get attached to the plate surface for $24 \mathrm{hrs}$. The cells were then starved for $24 \mathrm{hrs}$ by supplying serum-free (incomplete) DMEM. Sericin supplemented medium was prepared initially by adding different concentrations of sericin solution to incomplete DMEM. Finally, media containing 2 different concentrations $(0.05 \%$ and $0.1 \%)$ of sericin of each of the 4 species were prepared and used as supplement in cell culture medium. Each of these sericin supplemented media was filtered under sterile conditions using a $0.22 \mu \mathrm{m}$ filter. The previously starved cells were treated with the different concentrations of sericin supplemented media over a period of 3 days. L929 cells growing in serum supplemented DMEM and in serum-free DMEM were used as controls.

2.5.1. Cell Viability. The cell viability was estimated by the reduction of Alamar Blue as substrate. The cells grown in sericin supplemented media were incubated with Alamar Blue at $37^{\circ} \mathrm{C}$ for $3 \mathrm{hrs}$. At the end of the assay, the supernatant was taken and the absorbance was measured at $570 \mathrm{~nm}$ and $600 \mathrm{~nm}$. The percentage of Alamar Blue reduced was plotted as a function of cellular metabolic activity and viability. 
Alamar Blue assay was performed after $24 \mathrm{hrs}$ and $72 \mathrm{hrs}$ of sericin treatment of the cells.

2.5.2. Cell Morphology. Morphology of the cells was studied by visualizing the cells under inverted phase contrast microscope and fluorescence microscope (Leica, Germany).

2.5.3. Cell Attachment. L929 cell attachment in sericin supplemented DMEM was studied by measuring the number of cells attached to the surface of tissue culture well as a function of time. Confluent L929 cells grown in serum supplemented DMEM were trypsinized and $10^{5}$ cells per well were seeded onto the wells containing $0.05 \%$ sericin supplemented DMEM of B. mori, A. mylitta, A. assama, and $S$. ricini. The cell attachment study was performed after $2,4,6$, 8,10 , and $12 \mathrm{hrs}$ of seeding. Media supernatant was removed at every time point and the number of unattached cells was enumerated. The number of cells attached as obtained by deducting the number of unattached cells from total number of cells seeded was plotted against time. (We have not carried out any further work on sericin hope being a mutant cocoon, which contains mostly sericins. This unique bioengineered silk sericin hope needs to be evaluated more on different aspects).

2.6. Statistical Analysis. Experiments were run in triplicate per sample and each experiment was conducted at least thrice. All data were expressed as mean \pm standard deviation (SD) for $n=3$. A single-factor analysis of variance technique was used to determine the statistical significance of the results.

\section{Results}

3.1. Isolation of Sericin from the Cocoons. Sericins are isolated from the cocoons of A. mylitta, A. assama, S. ricini, and $B$. mori (Figure 1). They are processed, that is, dialyzed to remove salts, fats, and others, and finally concentrated. Different extraction methods produce variable yields of extracted sericin depending on the physical properties of cocoons. Silk sericin can be extracted by degumming silk cocoons using various chemical agents like urea, sodium chloride, sodium carbonate, and sodium hydroxide. Highest sericin yield is reported to be achieved via sodium carbonate treatment while urea method produces lowest amount of sericin [10]. Additionally, different species of silk are also known to have variable yields of sericin for any extraction method [10]. Nonchemical (autoclave) method shows variable degumming ratio in mulberry (18-21\%) and non-mulberry species (6$11 \%)$. At times, the variation in extracted amount of sericin from non-mulberry is very low and unpredictable even in the same species. What we understand is that several factors are involved in the variation of sericin yields like age/freshness, eco-races/strain, season, place of collection, type of crops (multivoltine/bivoltine), storage conditions, contamination (being wild), rearing procedure, handling of cocoons, and others [10]. The variations in the sericin content in mulberry and non-mulberry silk cocoons result in the differences of sericin yield in these species.

3.2. Scanning Electron Microscopy (SEM). SEM is carried out to observe the effect of degumming on the microstructures of the fibres of the cocoons. Figure 2 shows the SEM micrographs of cocoon pieces before and after degumming by $8 \mathrm{M}$ urea and boiling under pressure (autoclave method). The micrographs of nondegummed silk cocoons have white striations, indicating sericin, between the fibroin fibres, whereas the degummed fibres have minimal sericin between the fibres. The fibres are distinctly visible and well separated from one another due to the removal of the glue protein sericin, which holds them together.

\subsection{Characterization of Silk Sericins}

3.3.1. Estimation of Molecular Weight through SDS-PAGE. The sericins of different silkworm species extracted by autoclave method appear as smears in the $8 \%$ gel after electrophoresis (Figure 3). Heating of the cocoons under high pressure and temperature degrades the protein. On the other hand, sericin isolated by urea method separates the protein into various fractions, which appear as bands in the gel after the run (Figure 3). Marked differences are seen in sericin extracted from mulberry species from that in non-mulberry species. The sericin fractions obtained in case of $B$. mori and $A$. mylitta are comparable to results obtained previously [14]. B. mori sericin shows bands of $250 \mathrm{kDa}$ and $130 \mathrm{kDa}$, some in the range of $120-130 \mathrm{kDa}$, and a lower fraction of $17 \mathrm{kDa}$ [35]. A. mylitta sericin comprised mainly three fractions of approximately $250 \mathrm{kDa}, 200 \mathrm{kDa}$, and $70 \mathrm{kDa}$. $S$. ricini has two bands, one greater than $300 \mathrm{kDa}$ and one in the range of $200-250 \mathrm{kDa}$ (Figure 3). For A. assama one fraction greater than $250 \mathrm{kDa}$ and another approximately $90 \mathrm{kDa}$ are observed. As inferred by SDS-PAGE, sericin represents a family of proteins with a diverse distribution of molecular weights. Distinct fractions of sericin polypeptides are isolated in the urea method. It is shown that L929 cells grown in medium containing sericin extracted by urea method exhibited cytotoxicity [36]; therefore, this method is not used for preparing sericin supplemented medium in our study. However, to illustrate the different bands or fractions of the sericins from A. mylitta, A. assama, S. ricini, and B. mori in SDS-PAGE, sericins extracted by urea method are employed. The other methods used for extraction of sericins provide smears in gels [36]. As sericin hope consists of mostly sericin protein, it is therefore employed for comparison with sericin of B. mori, A. mylitta, and S. ricini by SDS-PAGE. No further work, apart from SDS-PAGE, is carried out with sericin hope for comparison. The autoclave method gives a smear in SDSPAGE indicating that the protein polypeptides are broken into smaller fractions. This autoclave method is chosen for further investigations as it is free of any toxic ions.

3.3.2. Circular Dichroism (CD) Spectroscopy. The CD spectrum of the cocoon sericin solutions of all species shows one sharp negative band at around $200 \mathrm{~nm}$ assigned to random 

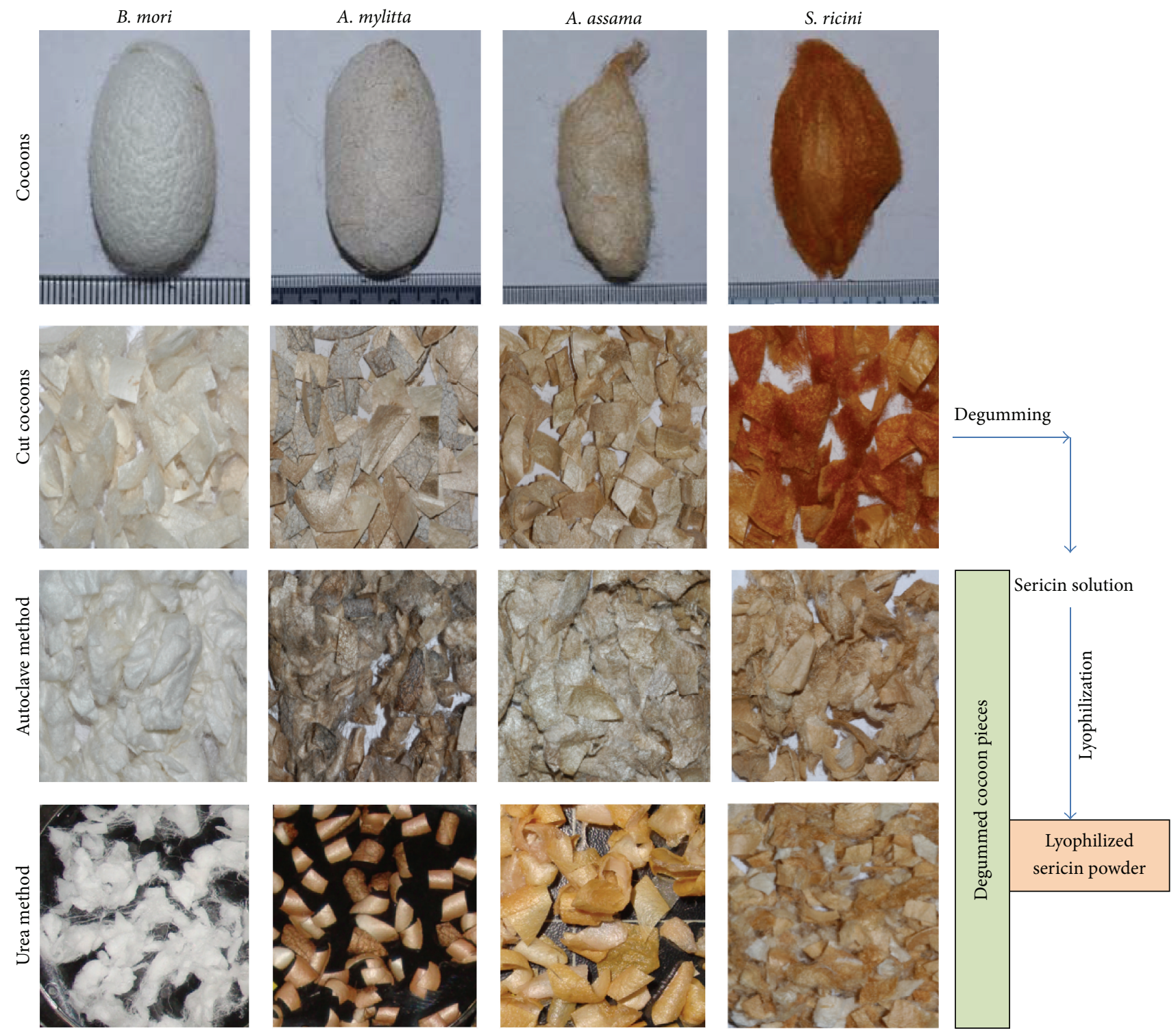

FIGURE 1: Degumming of silk cocoons of different species of silkworms using different methods of isolation of sericins.

coil conformation (Figure 4(a)). A negative band at $218 \mathrm{~nm}$ reveals the presence of $\beta$-sheet. The alpha helix content is low because of the absence of double minimum at $222 \mathrm{~nm}$ and $208-210 \mathrm{~nm}$ and a positive band at $190 \mathrm{~nm}$. The secondary structure data shows that the percentage of random coil is highest in S. ricini. Percentage of beta is highest in the wild species A. assama, followed by A. mylitta and B. mori, and the least in S. ricini. Small percentages of turns are seen in S. ricini and B. mori. They are absent in the other two species. Helix is present in very small amount in $A$. mylitta and negligible in A. assama. In spite of the presence of higher amount of glutamic acid and lower percentage of tyrosine, $\mathrm{CD}$ spectroscopy analysis of the secondary structure of the A. mylitta sericin reveals its $\beta$-sheet structure in native form. The $\beta$-sheet structure may be due to the polar zipper interaction through hydrogen bonding among abundant polar amino acids in the serine-rich repetitive motif [37].
It was reported previously that the $\beta$-sheet conformational structure of sericin in aqueous solution is stabilized by the hydration and electrostatic interactions [38].

3.3.3. Fourier Transform Infrared (FTIR) Spectroscopy. All the species have similar peaks at $1656.58 \mathrm{~cm}^{-1}$ (Amide I), $1540-1543 \mathrm{~cm}^{-1}$ (Amide II), and 1242-1246 (Amide III) (Figure 4(b)). The peak at $1656.58 \mathrm{~cm}^{-1}$ suggests the presence of $\alpha$-helix. The $\beta$-sheet aggregates help in stabilizing sericin in water, hence contributing to the strength of the cocoon and suitability as a biomaterial. The CD spectrum of all the species shows the presence of random coil conformation and $\beta$-sheets with a low content of alpha helix. In aqueous form, the transition from random coil to $\beta$-sheet is quicker whereas anhydrous form has fewer tendencies to change its conformation. Hence, in the FTIR, we find the protein of the 


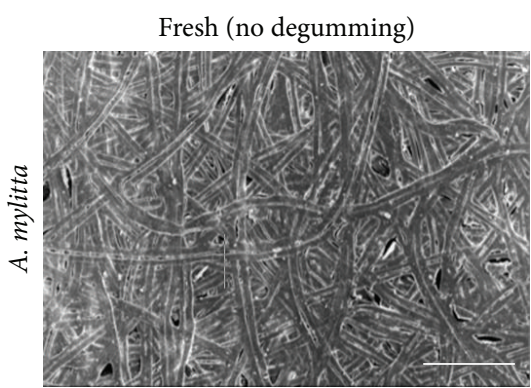

(a)

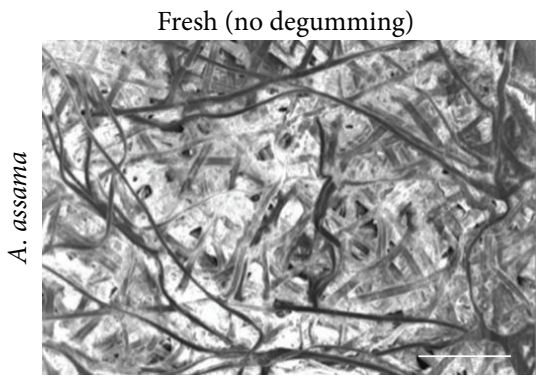

(d)

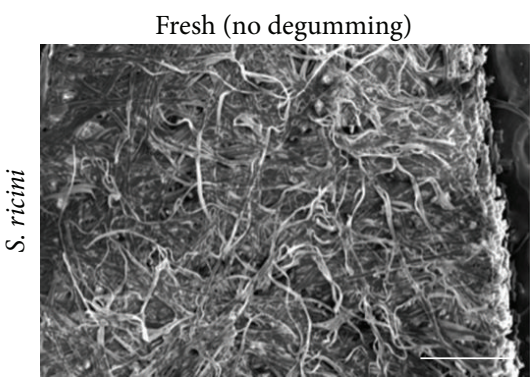

(g)

Fresh (no degumming)

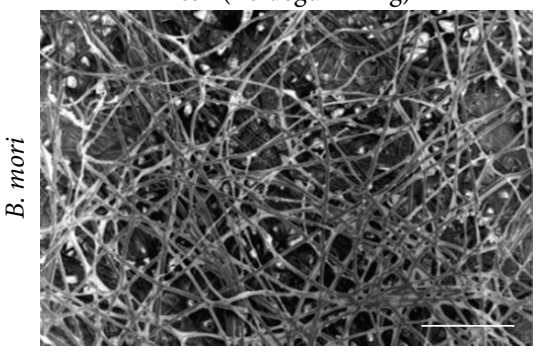

(j)

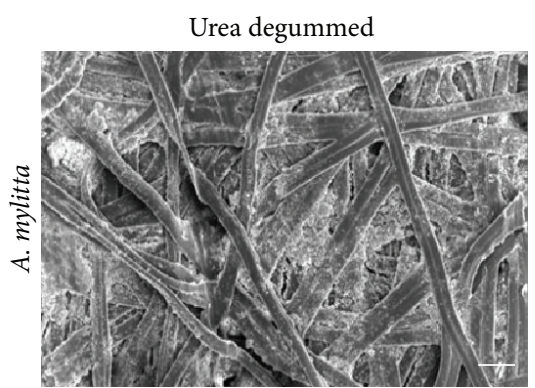

(b)

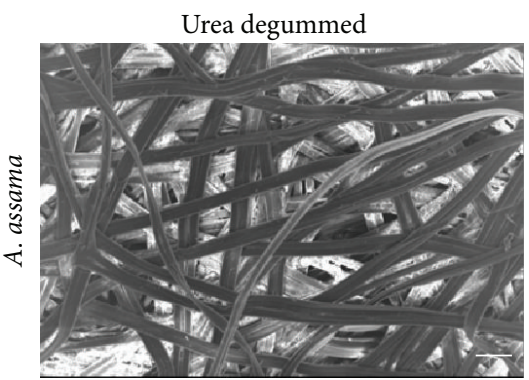

(e)

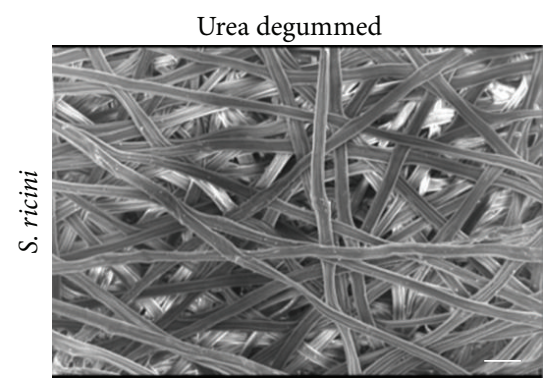

(h)

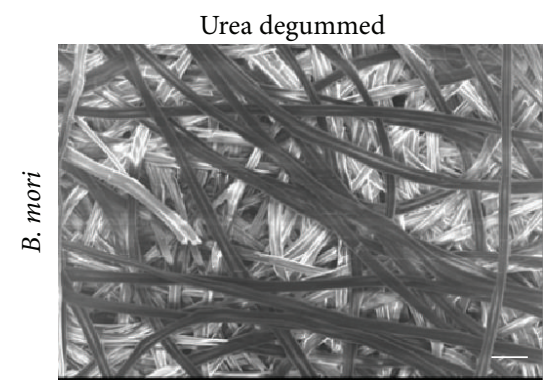

(k)

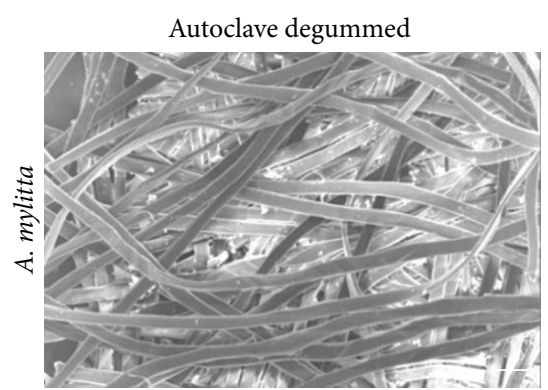

(c)

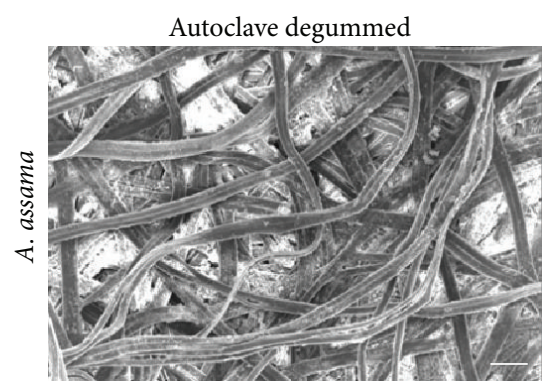

(f)

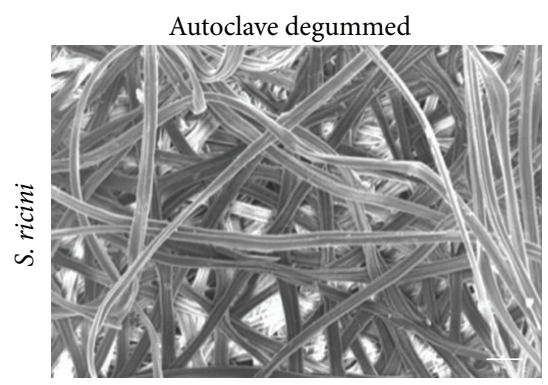

(i)

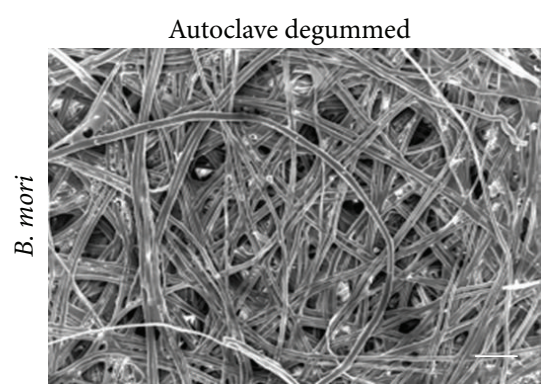

(1)

FIGURE 2: Scanning electron micrographs of the cocoon pieces of mulberry and non-mulberry silks. The cocoons are observed before (50x) and after degumming (100x) using urea and autoclave degumming methods. Scale bar represents $100 \mu \mathrm{m}$.

lyophilized powder as random coil and alpha helix, whereas the transition from the random coil to $\beta$-sheet is observed in $\mathrm{CD}$ results of aqueous solution of sericin.

3.3.4. Thermogravimetric Analysis. The thermogravimetric curves of sericin powders are shown in Figure 4(c). When comparing the graphs for the four samples, it is observed that the peaks in the DTG curve are the smallest for S. ricini sample and the largest for B. mori. This gives an indication that the rate of change in weight of the sample with time (or temperature) for S. ricini is more gradual than that for the sample of $B$. mori. Or in other words, S. ricini is thermally more stable than B. mori. A lower peak in the DTG curve means that the sample loses weight more steadily. Hence, the corresponding TGA curve is smoother and has lesser slopes at most times (and temperatures). By similar arguments and by observing the plots, the samples can be arranged in the following order of decreasing stability: S. ricini, A. assama, 


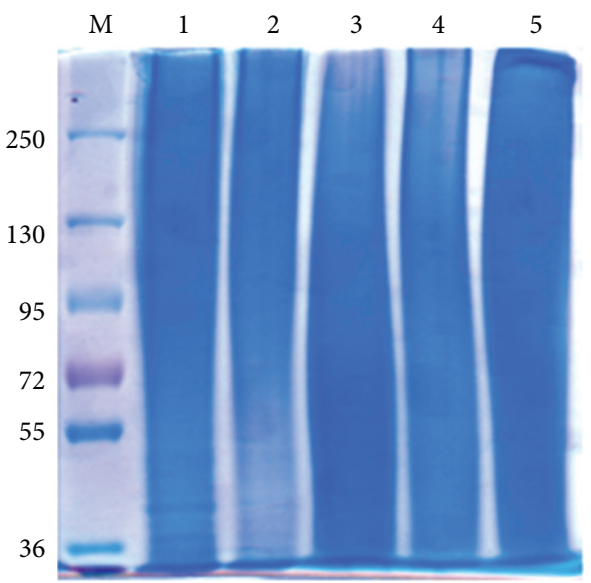

(a)

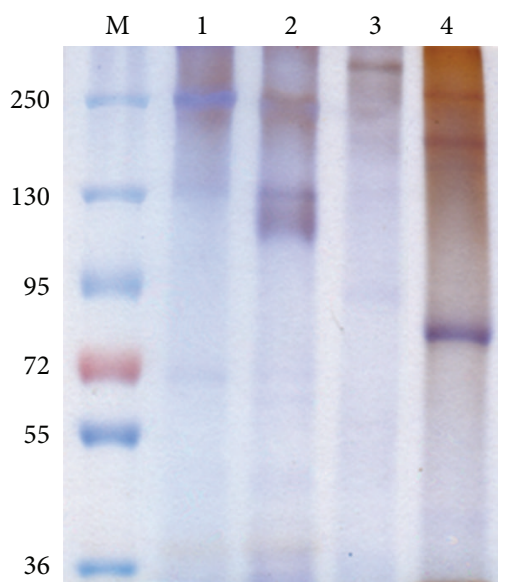

(b)

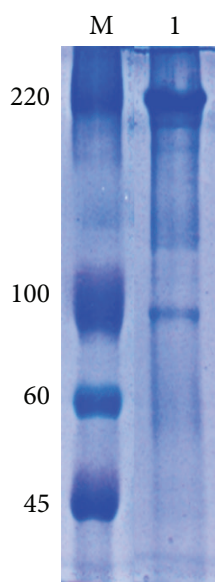

(c)

Figure 3: SDS-PAGE (8\%) analysis of $0.1 \%$ sericin solutions from cocoons of A. mylitta, B. mori, S. ricini, and A. assama: (a) isolated by autoclave method: Lane 1: sericin hope, Lane 2: B. mori, Lane 3: S. ricini, Lane 4: A. assama, and Lane 5: A. mylitta; (b) isolated by urea method: Lane 1: sericin hope, Lane 2: B. mori, Lane 3: S. ricini, and Lane 4: A. mylitta. (c) Lane 1: A. assama isolated by urea method. The protein molecular weight standards are indicated by the numbers on the left. M: molecular weight marker.

A. mylitta, and, lastly, sericin of B. mori. S. ricini is thermally more stable as compared to that of other species.

\subsection{Cell Culture}

3.4.1. Cell Attachment. The key in the attachment result is the time taken by cells to reach maximum attachment of cells in DMEM supplemented with $0.05 \%$ sericin of A. mylitta, A. assama, and S. ricini is comparable to that in serum supplemented and serum-free DMEM, which show maximum cell attachment at $10 \mathrm{hrs}$ after seeding (Figure 5). For media supplemented with $0.05 \%$ sericin of $B$. mori, maximum cell attachment is observed at $12 \mathrm{hrs}$ after seeding, which is in accordance with similar attachment study reported earlier [39]. After 4 hours of cell seeding, the percentage of cells attached in the case of serum-free medium was $99.75 \%$ and it remained approximately the same after 12 hours of seeding. However, in case of the cells growing in B. mori sericin supplemented medium, $98.5 \%$ cells were attached at 4 hours while the number increased to $99.48 \%$ after 12 hours. Percentage of the cells attached in non-mulberry sericin supplemented media at 4 hours and 12 hours was similar to that in serum-free media. The attachment of cells in B. mori sericin supplemented medium was almost similar in comparison to non-mulberry sericin and serum-free media. We can also say that non-mulberry sericin supported attachment faster than mulberry sericin. The final number of cells attached at 12 th hour for cells in serum-free medium and in mulberry supplemented medium does not have a statistical difference ( $p$ value $>0.05$ ). So, it can be concluded that somehow the mulberry sericin supplemented medium does promote cell attachment but at a rate slower than serum-free and non-mulberry sericin supplemented media. Furthermore, Tsubouchi et al. [40] reported that attachment is enhanced in mulberry sericin due to a repetitive fraction called sericin M $(170 \mathrm{kDa})$. No sericin protein fraction other than the
$\mathrm{M}$ fraction contributed to cell attachment. This $170 \mathrm{KDa}$ protein fraction is absent in our SDS-PAGE results. This could be a reason for slower attachment of cells in mulberry supplemented medium.

3.4.2. Cell Morphology. Cell morphology is studied by viewing the cells under inverted phase contrast microscope (Leica, Germany). The cells grown in normal complete DMEM are used as a control. In comparison with the control, the cells grown in sericin supplemented media show a marked morphology change as the concentration of sericin in the media is increased. The morphology of cells, as compared by phase contrast microscope, cultured in sericin supplemented media of B. mori and A. mylitta is comparable to the cells growing in $10 \%$ FBS supplemented control. However, morphology of the cells grown in S. ricini and A. assama sericin supplemented medium appears to be different (Figure 6(A)). Some morphological changes are observed when cells are cultured with $S$. ricini and $A$. assama sericin supplemented media. However, we have not studied the loss of phenotype or differentiation of cells into other types. The cells growing in control medium are typically spindle shaped. However, the sericin supplemented media did not negatively affect the actin cytoskeleton of the cells; fluorescence images show well-defined nuclei and actin microfilaments comparable to those of the cells grown in serum supplemented media (Figure 6(B)).

3.4.3. Cell Proliferation. Alamar Blue, a water soluble dye, is reduced by the cells growing in the medium, thereby changing the colour of the media from blue to pink which is measured colourimetrically. The number of viable cells correlates with the magnitude of dye reduction and is expressed as percentage of Alamar Blue reduced [41, 42]. Alamar assay conducted on L929 cells grown in sericin supplemented DMEM over a period of 3 days (Figure 7) shows that the 


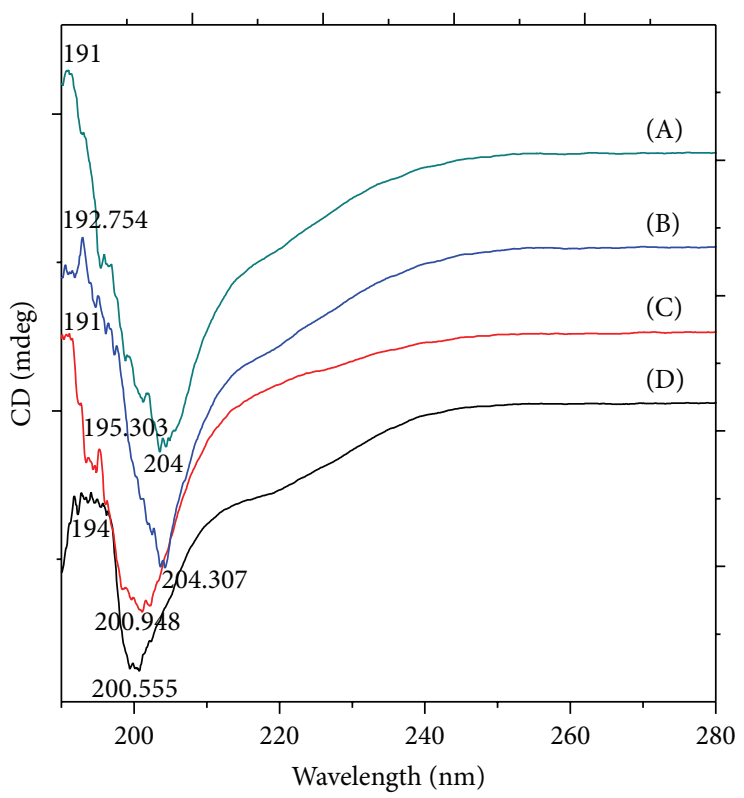

(a)

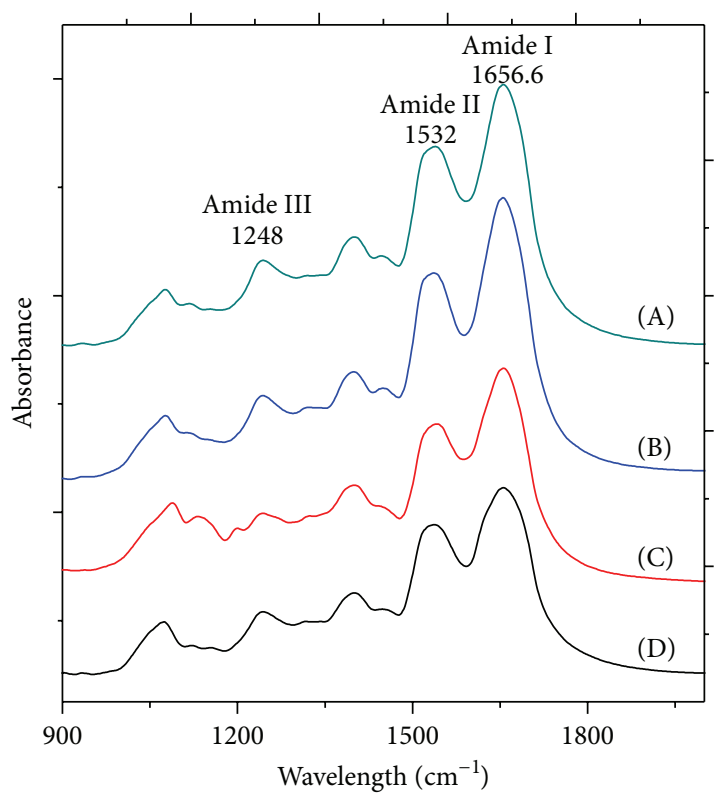

(b)

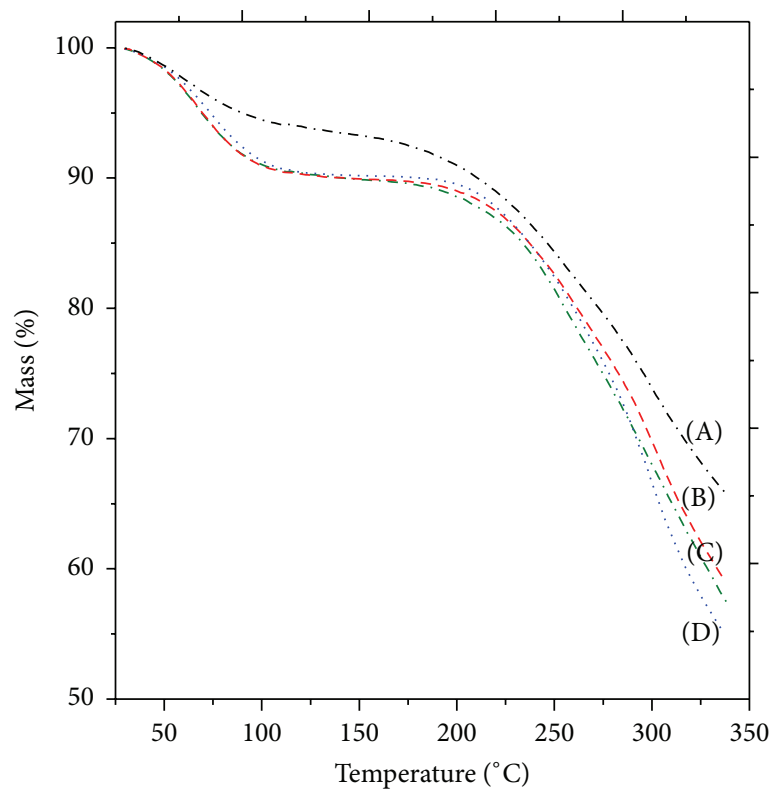

(c)

Figure 4: (a) CD spectra of $0.1 \%$ (w/v) sericin solution from cocoons of different species: (A) A. mylitta, (B) A. assama, (C) S. ricini, and (D) B. mori. (b) FTIR spectrum of sericin powders from the various species: (A) A. mylitta, (B) A. assama, (C) S. ricini, and (D) B. mori. (c) TGA curves of lyophilized sericin powders of (A) S. ricini, (B) A. mylitta, (C) A. assama, and (D) B. mori.

cells not only are viable but are also proliferating. This is comparable to that of the cells grown in serum-free DMEM. While sericin of $S$. ricini helps to proliferate the cells better over a period of 3 days, the other non-mulberry and mulberry sericins do not show a marked difference in proliferation. Even the growth of cells in $0.1 \%$ S. ricini sericin supplemented medium is also significantly greater than the cells growing in $10 \%$ serum supplemented medium. This is also found to be true for $0.05 \% \mathrm{~S}$. ricini sericin supplemented medium. Furthermore, the growth of cells in $0.05 \%$ B. mori, A. mylitta, and A. assama is found to be better than that of the cells growing in serum-free medium. There is a reduction on the growth of cells in serum-free medium from day one to day three. The cells grown in sericin supplemented media do not reflect the same. Based on the present cell culture assays the sericins of both mulberry and non-mulberry species appear to be beneficial to the growth of cells.

\section{Discussion}

Different sources of sericin show varied bands of different molecular weights depending on the silkworm species used as 


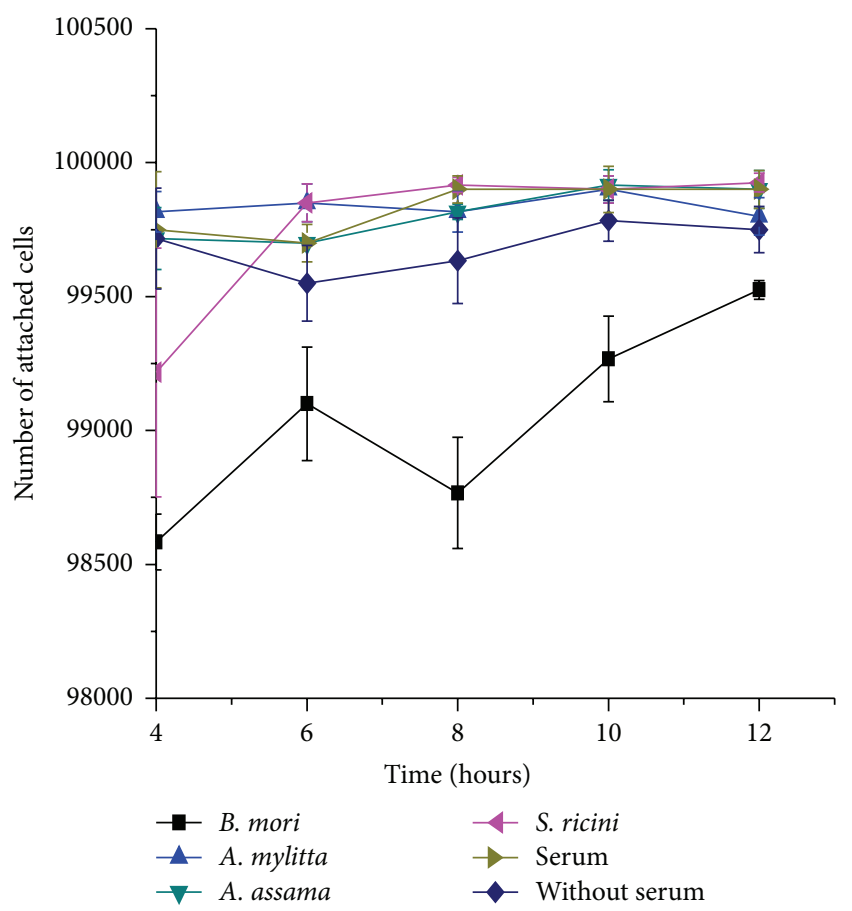

Figure 5: Time-dependent attachment of L929 cells growing in DMEM supplemented with $0.05 \%$ sericin of B. mori, A. mylitta, A. assama, and S. ricini sericin. Cells grown in DMEM supplemented with $10 \%$ serum and without serum were used as controls (error bars denote standard deviation for $n=3$ ).

the source of the protein when extracted using urea. This may lead to different chemical and biological properties, while harsh treatments (high temperature and pressure) tend to degrade the protein leading to the appearance of a smear in the gel. Amongst them the common one is seen around 200$250 \mathrm{kDa}$ along with certain low molecular weight sericin. Sericin-S, a small sericin having molecular weight 5 to $100 \mathrm{kDa}$ of $B$. mori, is believed to act as a mitogenic factor in serum-free media. This accelerates the proliferation of hybridoma cells and T-lymphocyte cells [22]. Novel sericinGIT medium, devoid of mammalian factors but containing sericin and other nutrients, helps in the proliferation of various cell lines, namely, HepG2, HeLa, SIRC, and L929 [43]. In our study, the silk fibroin fibres are seen to be clear of any remains of sericin when degummed properly indicating efficient extraction of sericin from the silk cocoon. Sericins show random coils and $\beta$-sheets in their secondary structures. This may be attributed to the polar interactions among the amino acids in the serine-rich motifs by hydrogen bonding leading to zipper like arrangements [37]. The transition from random coil to $\beta$-sheets in solution is stabilized by electrostatic interactions [38]. Thermal stability also differs in sericins. Sericin of S. ricini is seen to be most thermally stable amongst all. Sericins of mulberry and non-mulberry species are reported to have different biochemical properties [6]. While B. mori sericin comprises polypeptides ranging from 24 to $400 \mathrm{kDa}$, non-mulberry sericins also differ in molecular weights from one another. One major polypeptide fraction of $66 \mathrm{kDa}$ is identified in sericins of A. assama and $S$. ricini, while A. mylitta sericin consists of several polypeptide fractions ranging from 30 to $200 \mathrm{kDa}$ [6]. The two ranges of molecular weight-large sericin chain (MW 191-339 kDa) and small-size sericin (MW 61-132 kDa) are investigated for the apoptosis and proliferation of the colon cancer cells [44]. The smaller sericin had higher antiproliferative effects than that of the large sericin but neither of the sericin types (small or large sericin) affects the viability of the cells. So we can assume that the cell attachment will be similar, irrespective of the molecular weight of the sericins. Amino acid composition and secondary structure of A. mylitta sericin also vary from those of $B$. mori sericin [13]. Thus, the diversity of biochemical properties of silk sericins among different species of silkworms confers distinct biophysical properties to the sericins. The $400 \mathrm{kDa}$ sericin found in the middle portion of the $B$. mori silk gland, particularly its $170 \mathrm{kDa}$ fraction consisting of serine-rich repetitive domain, is reported to promote skin fibroblast attachment and activity. The sericins of anterior and posterior portions of $B$. mori silk grand show no biological effects in skin fibroblasts even though the posterior sericin has a $170 \mathrm{kDa}$ fraction but no serine-rich amino acid composition [40]. Thus, attachment and proliferation of cells depend not only on the presence of specific polypeptide fractions but also on the amino acid content in the particular fraction. The difference in attachment of cells grown in sericin supplemented medium of different silkworm species in our study may be attributed to the differences in biophysical properties of the sericins.

Sericin has several beneficial properties and has already proved to be one of the natural biomaterials for different biomedical applications $[6,45,46]$. This work indicates that sericin can be used as media supplements. Investigations in the field of tissue engineering and regenerative medicine require growth supplements (growth factors or proteins), which are commonly provided by serum. This work indicates that sericin can support and enhance the cell growth equivalent to serum minimizing the limitation associated with the use of serum.

Replacement of the fetal bovine serum with mulberry $B$. mori sericin is reported to be successful in the culture of rat islet cells [23]. It is known that despite the benefits of serum in cell culture, it hinders the recovery of cellular product from media during downstream processing. The incorporation of sericin in the design of better serum-free media, therefore, may find better place in industries where cellular products of high purity are required. Media used for tissue culture may have significant effects on the growth and morphology of cells $[47,48]$. In a departure from similar studies that report the use of $B$. mori sericin as a serum substitute in the growth of fibroblast cells [36, 49], our study shows that the low concentrations of both mulberry and non-mulberry sericin supplemented media can be used as supplements to serum-free media. The differences in the morphology of the cells are observed in cells cultured in media supplemented with sericin of S. ricini and A. assama. Sericin is known to affect different pathways due to its antioxidant properties $[3,50-52]$. The morphological changes may be attributed to the effect of sericin on certain signalling pathway. Sericin 

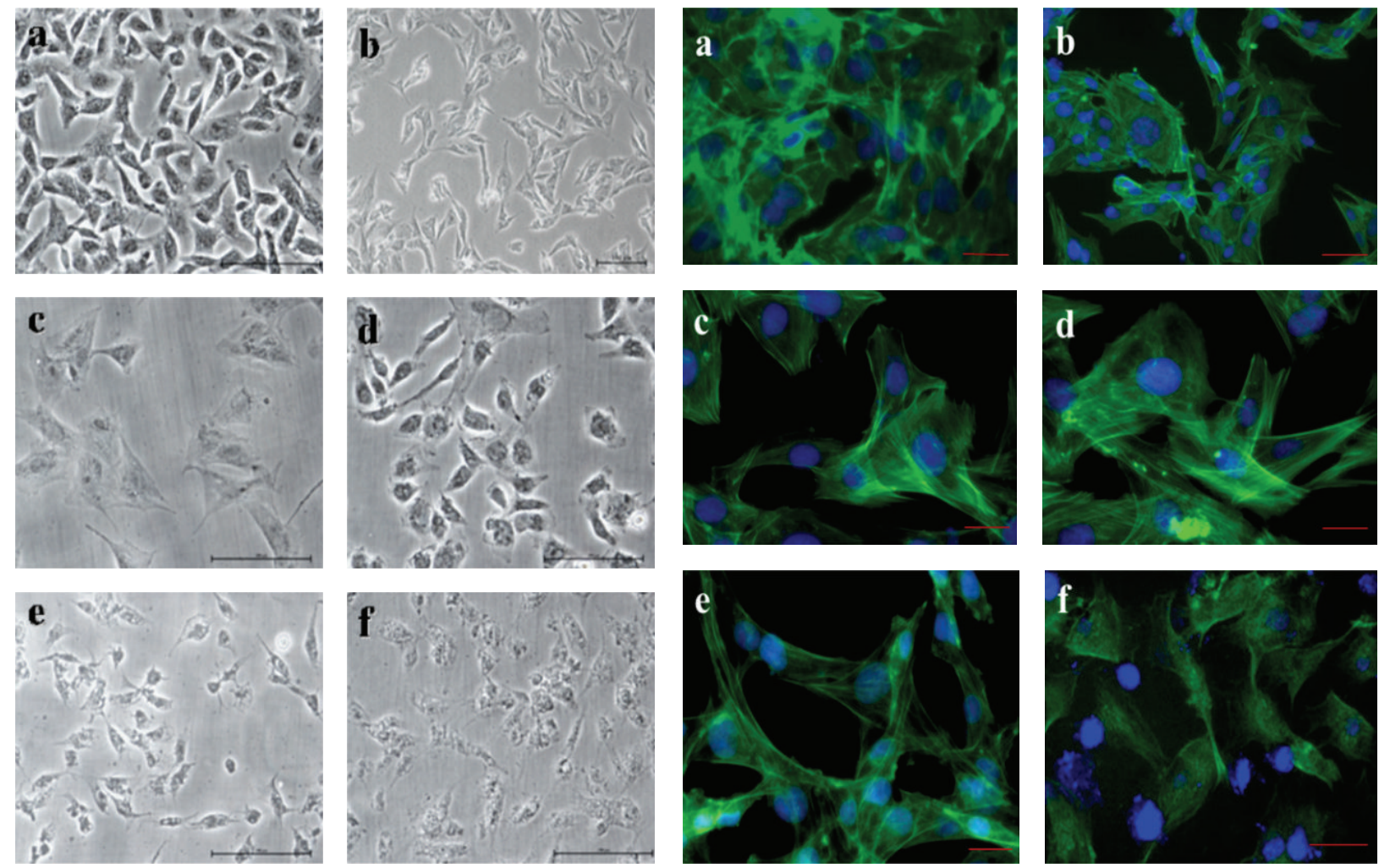

(A)

(B)

Figure 6: (A) Phase contrast and (B) fluorescence microscopic observations showing L929 fibroblasts growth and attachment on (a) 10\% serum supplemented DMEM and (b) serum-free DMEM as controls and in DMEM supplemented with $0.05 \%$ silk protein sericins of $B$. mori (c), A. mylitta (d), A. assama (e), and S. ricini (f). Scale bar represents $10 \mu \mathrm{m}$.

supplemented media do not seem to negatively affect the actin cytoskeleton of the cells as fluorescence images show well-defined nuclei and actin microfilaments comparable to those of serum supplemented media (Figure 6(B)).

Sericins extracted by different methods were reported to exhibit different physical and biological properties [36]. Sericins consist of different fractions in each species. The extracted quantity of sericins and its fractions depend upon the source of materials, age, storage condition, and extraction protocol [10]. In the autoclave method, we observe only smears in the gels due to extreme conditions used in the extraction procedure. However, the individual fraction can be purified by other extraction methods but the detailed study based on the above parameters is yet to be carried out for each species. The sericins used in the cell culture of this study comprise all the fractions together of a particular species. Out of various methods of extraction, heat-degraded extraction of sericin proved to be least toxic and produced highest collagen in fibroblast cells and a concentration of $100 \mu \mathrm{g} / \mathrm{mL}$ seemed to be optimal for use in serum-free growth medium [51]. Therefore, in our study, heat-extracted sericins were used in serum-free culture medium. The cells grown in sericin supplemented media from A. mylitta and B. mori depict not only good cell viability but also proper cell morphology that is comparable to serum supplemented media (Figures 6(A)(c, d) and $6(B)(c, d))$. Therefore, as low as $0.05 \%$ sericins from
B. mori and A. mylitta can be used as potential medium supplements for the culture of L929 fibroblast cells. The authors do not claim at this stage that sericin can completely replace serum supplementation in different kinds of cells. However, in dealing with delicate cell cultures that are prone to serum shock, the sericin may act as a growth supplement. The effects of concentration of sericin in the growth medium are reported to affect the cell viability and growth. In a similar study, mulberry sericin extracted by heat-degradation or autoclave method had been shown to enhance the proliferation of L929 cells in the medium supplemented with $0.03 \%$ B. mori sericin while the cell viability decreased considerably at higher sericin concentration of $0.3 \%$ [53]. Furthermore, Aramwit et al. reported that a low concentration of $8 \mu \mathrm{g} / \mathrm{mL}$ heat-degraded sericin showed highest cell viability in mouse fibroblast cells while higher concentrations of sericin in the medium significantly decreased cell viability [36]. In our study, viability increased when the cells were grown in $0.05 \%$ sericin of non-mulberry species during the course of 3 days. S. ricini sericin showed the highest increase in viability. However, the viability of cells growing in $0.1 \%$ sericin did not change as effectively when compared with cells growing in $0.05 \%$ sericin supplemented medium. Thus, the results indicate that the growth and viability of cells depend on the concentration of sericin in the medium. The results indicate that further investigations are to be conducted to determine 


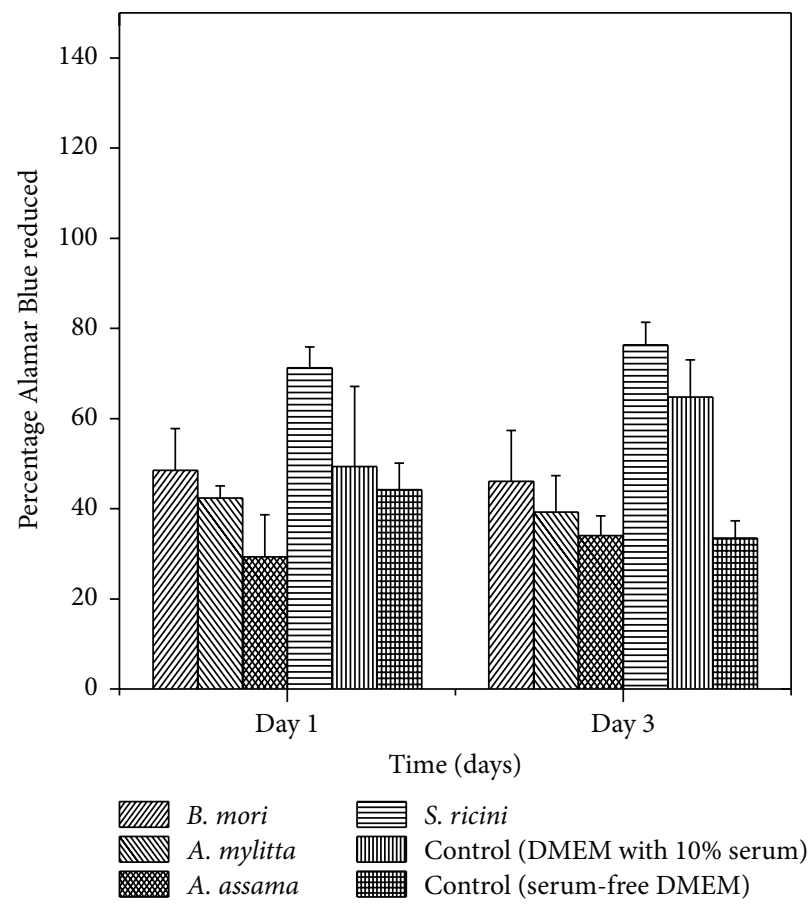

(a)

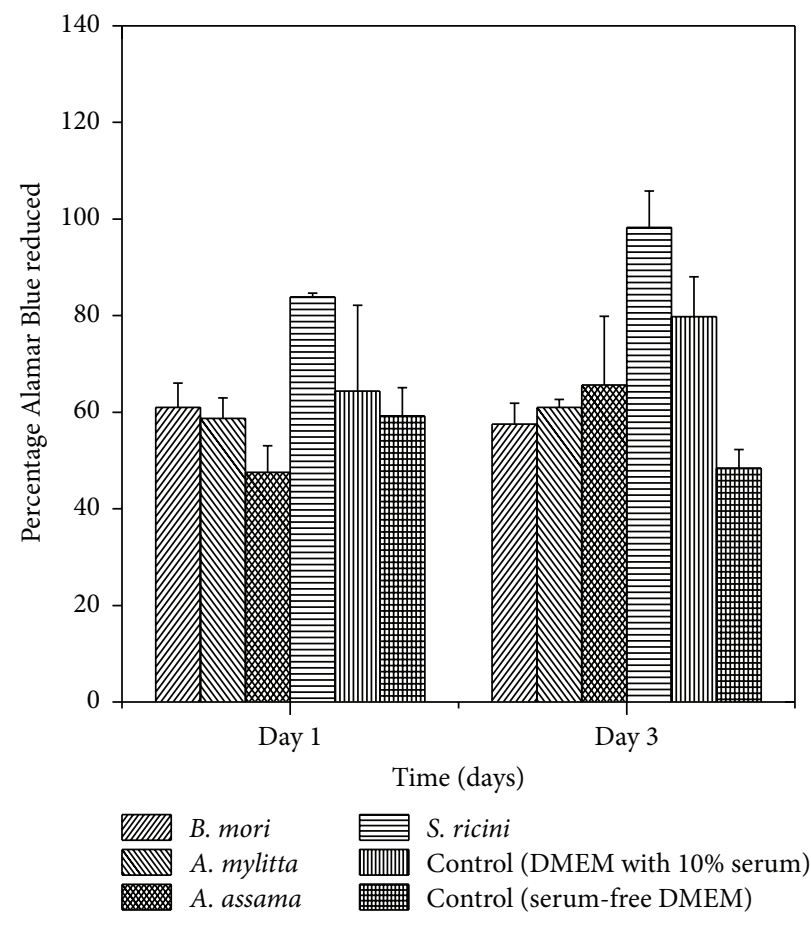

(b)

Figure 7: Estimation of cell viability and proliferation by Alamar Blue assay on L929 cells grown on $0.1 \%$ (a) and $0.05 \%$ (b) concentrations of sericin of B. mori, A. mylitta, A. assama, and S. ricini, 10\% FBS supplemented DMEM and FBS free DMEM (error bars denote standard deviation for $n=3$ ).

how sericin regulates the different cellular morphology and functions. This requires optimizing the dosage for each species of sericin for different cell lines. The present work attempts to present that both mulberry and different nonmulberry silk protein sericins play an important role in cell culture.

\section{Conclusion}

Sericins from mulberry and different non-mulberry species usually depict that more stable $\beta$-sheets conformation is solution, which adds to its integrity in aqueous media. Different molecular weights of sericin may be determining the difference in the properties of sericin from different sources like thermal stability and cytocompatibility. The low concentrations $(0.05 \%)$ of all the different sources of sericins supplemented media show better cell growth than serumfree media. This indicates that sericin supports both the attachment and growth of the cells. The morphology of cells cultured in sericin supplemented media from mulberry Bombyx mori and non-mulberry Antheraea mylitta is comparable to that of the cells grown in medium supplemented with $10 \%$ FBS. There is a change in the morphology of the cells grown in Samia ricini and Antheraea assama sericin supplemented media and the cause for the change needs attention. Sericins of both mulberry and non-mulberry species have the potential to be used as a substitute for serum in media for the growth of cells. The sericins are low-cost, abundant, waste/byproduct of textile industries and are underutilised materials. Further investigations are needed to understand how sericins aid in the growth and proliferation of cells and their behavior of different sources.

\section{Disclosure}

Neety Sahu present address is Department of Chemical and Bimolecular Engineering, 207 Othmer Hall, University of Nebraska-Lincoln, Lincoln, NE 68588-0643, USA. Dr. Joydip Kundu present address is Department of Chemical Engineering, 313 Snell Engineering Centre, Northeastern University, 360 Huntington Avenue, Boston, MA 02115-5000, USA. Dr. Sarmistha Talukdar present address is Virginia Commonwealth University, Institute of Molecular Medicine, Molecular Medicine Research Building, 1220 East Broad Street, 7th Floor, Richmond, VA 23298-0033, USA.

\section{Competing Interests}

The authors declare that they have no conflict of interests.

\section{Authors' Contributions}

Neety Sahu, Shilpa Pal, and Sunaina Sapru contributed equally to this work. 


\section{Acknowledgments}

The authors are thankful to Dr. Milli Banerjee, Directorate of Textile (Sericulture), and Mr. Mrinal Dey of State Ericulture Farm, Jalpaiguri, and to Dr. Monoj K. Baidya, Dr. Narayan Biswas, and Mr. Ram Kumar Saha of Central Silk Board, Cooch Behar, West Bengal State of India, for providing the eri and muga cocoons. The authors are also thankful to Sericulture Directorate, West Midnapore, West Bengal State, India, for providing mulberry cocoons. This work is supported by Department of Biotechnology and Indian Council of Medical Research Government of India, New Delhi.

\section{References}

[1] L. Lamboni, M. Gauthier, G. Yang, and Q. Wang, "Silk sericin: a versatile material for tissue engineering and drug delivery," Biotechnology Advances, vol. 33, no. 8, pp. 1855-1867, 2015.

[2] K. Yanagihara, M. Miki, A. Ogawa, M. Sasaki, H. Yamada, and S. Terada, "Effects of sericin on promoting proliferation and inhibiting apoptosis of mammalian cells," in Animal Cell Technology: Basic \& Applied Aspects, S. Shirahata, K. Ikura, M. Nagao, A. Ichikawa, and K. Teruya, Eds., vol. 15 of Animal Cell Technology: Basic \& Applied Aspects, pp. 31-36, 2009.

[3] R. Dash, M. Mandal, S. K. Ghosh, and S. C. Kundu, "Silk sericin protein of tropical tasar silkworm inhibits UVB-induced apoptosis in human skin keratinocytes," Molecular and Cellular Biochemistry, vol. 311, no. 1-2, pp. 111-119, 2008.

[4] B. C. Dash, B. B. Mandal, and S. C. Kundu, "Silk gland sericin protein membranes: fabrication and characterization for potential biotechnological applications," Journal of Biotechnology, vol. 144, no. 4, pp. 321-329, 2009.

[5] B. B. Mandal and S. C. Kundu, "Self-assembled silk sericin/ poloxamer nanoparticles as nanocarriers of hydrophobic and hydrophilic drugs for targeted delivery," Nanotechnology, vol. 20, no. 35, Article ID 355101, 2009.

[6] S. C. Kundu, B. C. Dash, R. Dash, and D. L. Kaplan, "Natural protective glue protein, sericin bioengineered by silkworms: potential for biomedical and biotechnological applications," Progress in Polymer Science, vol. 33, no. 10, pp. 998-1012, 2008.

[7] S. Nayak, S. Dey, and S. C. Kundu, "Skin equivalent tissueengineered construct: co-cultured fibroblasts/ keratinocytes on 3D matrices of sericin hope cocoons," PLoS ONE, vol. 8, no. 9, article e74779, 2013.

[8] S. K. Das, T. Dey, and S. C. Kundu, "Fabrication of sericin nanoparticles for controlled gene delivery," RSC Advances, vol. 4, no. 5, pp. 2137-2142, 2014.

[9] T. Isobe, Y. Ikebata, T. Onitsuka et al., "Effect of sericin on preimplantation development of bovine embryos cultured individually," Theriogenology, vol. 78, no. 4, pp. 747-752, 2012.

[10] B. Kundu, N. E. Kurland, V. K. Yadavalli, and S. C. Kundu, "Isolation and processing of silk proteins for biomedical applications," International Journal of Biological Macromolecules, vol. 70, pp. 70-77, 2014.

[11] H. Mosher and J. Rayon, "The sericin fractions of silk," American Silk, vol. 53, pp. 43-44, 1934.

[12] Y. Takasu, H. Yamada, and K. Tsubouchi, "Isolation of three main sericin components from the cocoon of the silkworm, Bombyx mori," Bioscience, Biotechnology and Biochemistry, vol. 66 , no. 12, pp. 2715-2718, 2002.
[13] R. Dash, S. Mukherjee, and S. C. Kundu, "Isolation, purification and characterization of silk protein sericin from cocoon peduncles of tropical tasar silkworm, Antheraea mylitta," International Journal of Biological Macromolecules, vol. 38, no. 3-5, pp. 255258, 2006.

[14] R. Dash, S. K. Ghosh, D. L. Kaplan, and S. C. Kundu, "Purification and biochemical characterization of a $70 \mathrm{kDa}$ sericin from tropical tasar silkworm, Antheraea mylitta," Comparative Biochemistry and Physiology-B Biochemistry and Molecular Biology, vol. 147, no. 1, pp. 129-134, 2007.

[15] H. Yun, H. Oh, M. K. Kim et al., "Extraction conditions of Antheraea mylitta sericin with high yields and minimum molecular weight degradation," International Journal of Biological Macromolecules, vol. 52, no. 1, pp. 59-65, 2013.

[16] N. E. Kurland, J. Kundu, S. Pal, S. C. Kundu, and V. K. Yadavalli, "Self-assembly mechanisms of silk protein nanostructures on two-dimensional surfaces," Soft Matter, vol. 8, no. 18, pp. 49524959, 2012.

[17] J. T. B. Shaw and S. G. Smith, "Amino-acids of silk sericin," Nature, vol. 168, no. 4278, p. 745, 1951.

[18] S. Nayak, T. Dey, D. Naskar, and S. C. Kundu, "The promotion of osseointegration of titanium surfaces by coating with silk protein sericin," Biomaterials, vol. 34 , no. 12, pp. 2855-2864, 2013.

[19] T. Siritienthong, J. Ratanavaraporn, and P. Aramwit, "Development of ethyl alcohol-precipitated silk sericin/polyvinyl alcohol scaffolds for accelerated healing of full-thickness wounds," International Journal of Pharmaceutics, vol. 439, no. 1-2, pp. 175186, 2012.

[20] S. Kanokpanont, S. Damrongsakkul, J. Ratanavaraporn, and P. Aramwit, "An innovative bi-layered wound dressing made of silk and gelatin for accelerated wound healing," International Journal of Pharmaceutics, vol. 436, no. 1-2, pp. 141-153, 2012.

[21] B. Kundu and S. C. Kundu, "Silk sericin/polyacrylamide in situ forming hydrogels for dermal reconstruction," Biomaterials, vol. 33, no. 30, pp. 7456-7467, 2012.

[22] S. Terada, M. Sasaki, K. Yanagihara, and H. Yamada, "Preparation of silk protein sericin as mitogenic factor for better mammalian cell culture," Journal of Bioscience and Bioengineering, vol. 100, no. 6, pp. 667-671, 2005.

[23] M. Morikawa, T. Kimura, M. Murakami, K. Katayama, S. Terada, and A. Yamaguchi, "Rat islet culture in serum-free medium containing silk protein sericin," Journal of HepatoBiliary-Pancreatic Surgery, vol. 16, no. 2, pp. 223-228, 2009.

[24] A. Ogawa, S. Terada, T. Kanayama et al., "Improvement of islet culture with sericin," Journal of Bioscience and Bioengineering, vol. 98, no. 3, pp. 217-219, 2004.

[25] M. Takahashi, K. Tsujimoto, H. Yamada, H. Takagi, and S. Nakamori, "The silk protein, sericin, protects against cell death caused by acute serum deprivation in insect cell culture," Biotechnology Letters, vol. 25, no. 21, pp. 1805-1809, 2003.

[26] M. Sasaki, Y. Kato, H. Yamada, and S. Terada, "Development of a novel serum-free freezing medium for mammalian cells using the silk protein sericin," Biotechnology and Applied Biochemistry, vol. 42, no. 2, pp. 183-188, 2005.

[27] T. Isobe, Y. Ikebata, T. Onitsuka et al., "Cryopreservation for bovine embryos in serum-free freezing medium containing silk protein sericin," Cryobiology, vol. 67, no. 2, pp. 184-187, 2013.

[28] K. Ohnishi, M. Murakami, M. Morikawa, and A. Yamaguchi, "Effect of the silk protein sericin on cryopreserved rat islets," Journal of Hepato-Biliary-Pancreatic Sciences, vol. 19, pp. 354360, 2012. 
[29] M. Verdanova, R. Pytlik, and M. H. Kalbacova, "Evaluation of sericin as a fetal bovine serum-replacing cryoprotectant during freezing of human mesenchymal stromal cells and human osteoblast-like cells," Biopreservation and Biobanking, vol. 12, no. 2, pp. 99-105, 2014.

[30] S. J. Froud, "The development, benefits and disadvantages of serum-free media," Developments in Biological Standardization, vol. 99, pp. 157-166, 1999.

[31] B. B. Mandal, A. S. Priya, and S. C. Kundu, "Novel silk sericin/gelatin 3-D scaffolds and 2-D films: fabrication and characterization for potential tissue engineering applications," Acta Biomaterialia, vol. 5, no. 8, pp. 3007-3020, 2009.

[32] Y.-Q. Zhang, M.-L. Tao, W.-D. Shen et al., "Immobilization of L-asparaginase on the microparticles of the natural silk sericin protein and its characters," Biomaterials, vol. 25, no. 17, pp. 37513759, 2004.

[33] H. Blum, H. Beier, and H. J. Gross, "Improved silver staining of plant proteins, RNA and DNA in polyacrylamide gels," Electrophoresis, vol. 8, no. 2, pp. 93-99, 1987.

[34] J. T. Yang, C.-S. C. Wu, and H. M. Martinez, "Calculation of protein conformation from circular dichroism," Methods in Enzymology, vol. 130, pp. 208-269, 1986.

[35] Y. Takasu, H. Yamada, H. Saito, and K. Tsubouchi, "Characterization of Bombyx mori sericins by the partial amino acid sequences," Journal of Insect Biotechnology and Sericology, vol. 74, no. 3, pp. 103-109, 2005.

[36] P. Aramwit, S. Kanokpanont, T. Nakpheng, and T. Srichana, "The effect of sericin from various extraction methods on cell viability and collagen production," International Journal of Molecular Sciences, vol. 11, no. 5, pp. 2200-2211, 2010.

[37] J. Huang, R. Valluzzi, E. Bini, B. Vernaglia, and D. L. Kaplan, "Cloning, expression, and assembly of sericin-like protein," The Journal of Biological Chemistry, vol. 278, no. 46, pp. 46117-46123, 2003.

[38] S. Urushizaki, “The stability of sericin aqueous solution," Sanshi Kenkyu, vol. 99, pp. 71-74, 1976.

[39] S. Talukdar, M. Mandal, D. W. Hutmacher, P. J. Russell, C. Soekmadji, and S. C. Kundu, "Engineered silk fibroin protein 3D matrices for in vitro tumor model," Biomaterials, vol. 32, no. 8, pp. 2149-2159, 2011.

[40] K. Tsubouchi, Y. Igarashi, Y. Takasu, and H. Yamada, "Sericin enhances attachment of cultured human skin fibroblasts," Bioscience, Biotechnology and Biochemistry, vol. 69, no. 2, pp. 403405, 2005.

[41] P. Goegan, G. Johnson, and R. Vincent, "Effects of serum protein and colloid on the alamarBlue assay in cell cultures," Toxicology in Vitro, vol. 9, no. 3, pp. 257-266, 1995.

[42] M. M. Nociari, A. Shalev, P. Benias, and C. Russo, "A novel one-step, highly sensitive fluorometric assay to evaluate cellmediated cytotoxicity," Journal of Immunological Methods, vol. 213, no. 2, pp. 157-167, 1998.

[43] M. Kobayashi, A. Sakuma, Y. Kunitomi, M. Sasaki, H. Yamada, and S. Terada, "Development of mammalian factors-free medium for cell culture by using silk protein sericin," Journal of Bioscience and Bioengineering, vol. 108, pp. S18-S19, 2009.

[44] W. Kaewkorn, N. Limpeanchob, W. Tiyaboonchai, S. Pongcharoen, and M. Sutheerawattananonda, "Effects of silk sericin on the proliferation and apoptosis of colon cancer cells," Biological Research, vol. 45, no. 1, pp. 45-50, 2012.
[45] P. Aramwit, T. Siritientong, and T. Srichana, "Potential applications of silk sericin, a natural protein from textile industry byproducts," Waste Management and Research, vol. 30, no. 3, pp. 217-224, 2012.

[46] T.-T. Cao and Y.-Q. Zhang, "Processing and characterization of silk sericin from Bombyx mori and its application in biomaterials and biomedicines," Materials Science and Engineering C, vol. 61, pp. 940-952, 2016.

[47] H. Shafaei, A. Esmaeili, M. Mardani et al., "Effects of human placental serum on proliferation and morphology of human adipose tissue-derived stem cells," Bone Marrow Transplantation, vol. 46, no. 11, pp. 1464-1471, 2011.

[48] U. Osuna-Martínez, A. Gómez-Solís, E. Alvarez-Ayala, J. ReyesEsparza, and L. Rodriguez-Fragoso, "Effect of porcine-serum on viability, proliferation and morphology of hepatic cells," The FASEB Journal, vol. 24, no. 1, supplement, p. 965.11, 2010.

[49] T.-T. Cao and Y.-Q. Zhang, "Viability and proliferation of L929, tumour and hybridoma cells in the culture media containing sericin protein as a supplement or serum substitute," Applied Microbiology and Biotechnology, vol. 99, no. 17, pp. 7219-7228, 2015.

[50] N. Kato, S. Sato, A. Yamanaka, H. Yamada, N. Fuwa, and M. Nomura, "Silk protein, sericin, inhibits lipid peroxidation and tyrosinase activity," Bioscience, Biotechnology, and Biochemistry, vol. 62, no. 1, pp. 145-147, 1998.

[51] J.-B. Fan, L.-P. Wu, L.-S. Chen, X.-Y. Mao, and F.-Z. Ren, "Antioxidant activities of silk sericin from silkworm Bombyx mori," Journal of Food Biochemistry, vol. 33, no. 1, pp. 74-88, 2009.

[52] P. Qian, S. Ai, H. Yin, and J. Li, "Evaluation of DNA damage and antioxidant capacity of sericin by a DNA electrochemical biosensor based on dendrimer-encapsulated $\mathrm{Au}-\mathrm{Pd} /$ chitosan composite," Microchimica Acta, vol.168, no. 3, pp. 347-354, 2010.

[53] S. Terada, T. Nishimura, M. Sasaki, H. Yamada, and M. Miki, "Sericin, a protein derived from silkworms, accelerates the proliferation of several mammalian cell lines including a hybridoma," Cytotechnology, vol. 40, no. 1-3, pp. 3-12, 2002. 


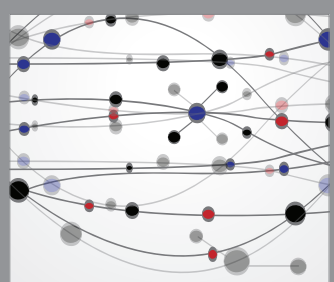

The Scientific World Journal
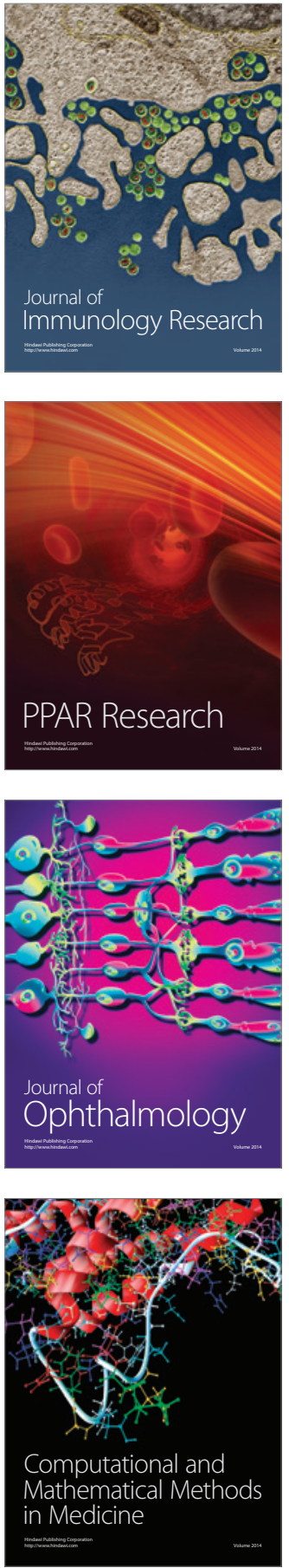

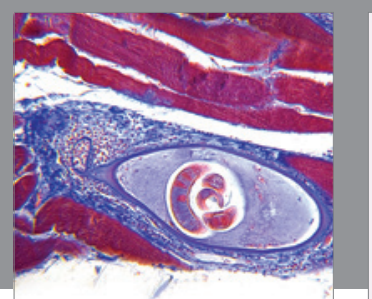

Gastroenterology Research and Practice

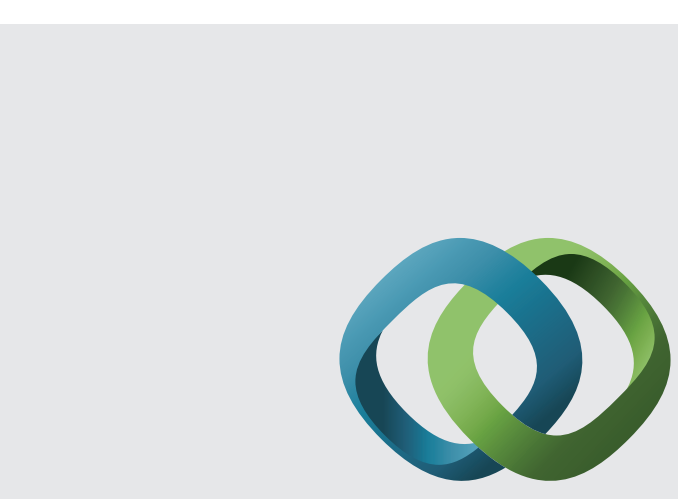

\section{Hindawi}

Submit your manuscripts at

http://www.hindawi.com
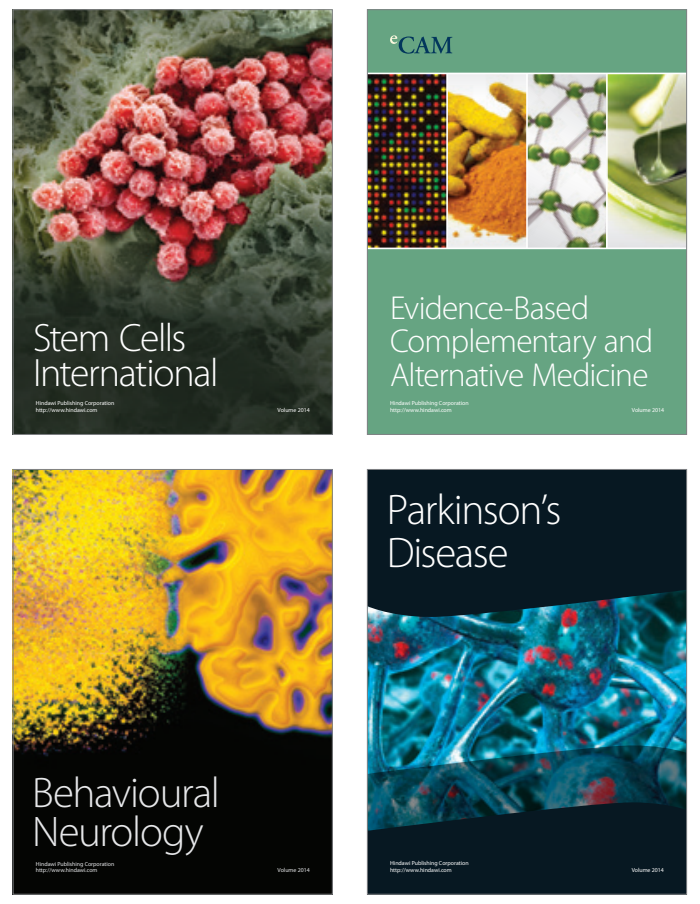
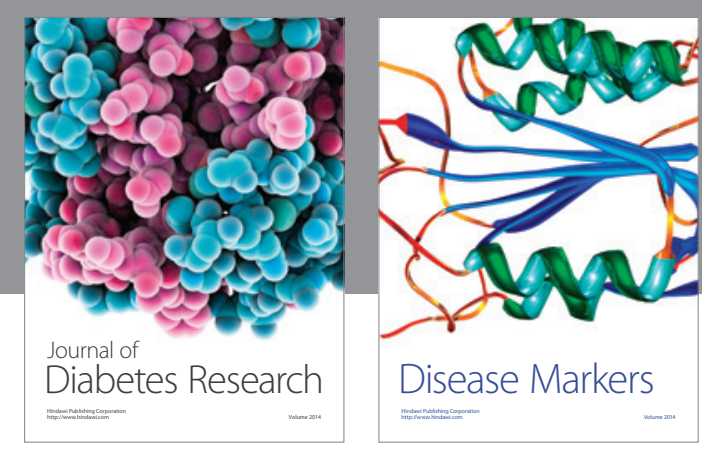

Disease Markers
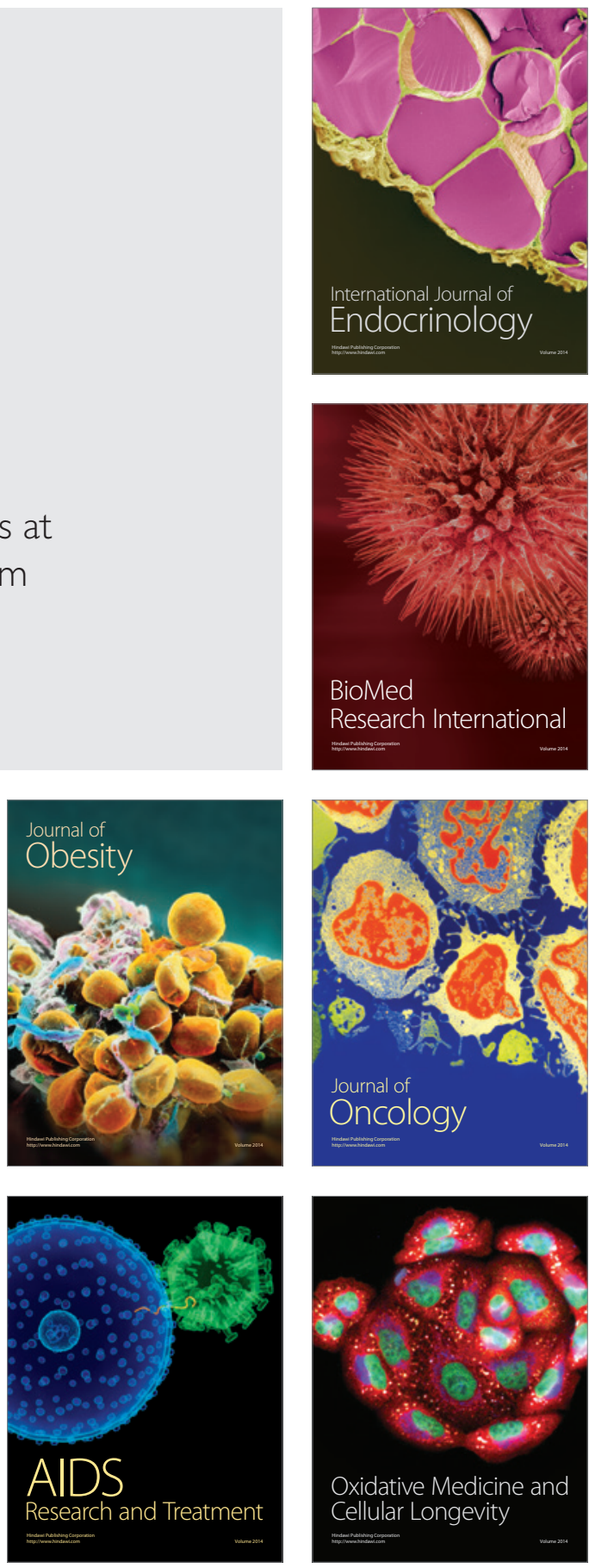